\title{
Regulation of DNA Double Strand Breaks Processing: Focus on Barriers
}

OPEN ACCESS

Edited by:

Pablo Huertas,

Centro Andaluz de Biología Molecular

y Medicina Regenerativa

(CABIMER), Spain

Reviewed by:

Greg Ira,

Baylor College of Medicine,

United States

Atsushi Shibata,

Gunma University, Japan

*Correspondence:

Achille Pelliciol

achille.pellicioli@unimi.it

tPresent Address:

Chetan C. Rawal,

Molecular and Computational Biology Department, University of Southern

California, Los Angeles, CA, United States

Specialty section:

This article was submitted to

Cellular Biochemistry,

a section of the journal

Frontiers in Molecular Biosciences

Received: 06 June 2019

Accepted: 01 July 2019

Published: 16 July 2019

Citation:

Marini F, Rawal CC, Liberi G and Pellicioli A (2019) Regulation of DNA Double Strand Breaks Processing: Focus on Barriers.

Front. Mol. Biosci. 6:55. doi: 10.3389/fmolb.2019.00055

\author{
Federica Marini ${ }^{1}$, Chetan C. Rawal ${ }^{17}$, Giordano Liberi ${ }^{2,3}$ and Achille Pellicioli ${ }^{1 *}$ \\ 'Dipartimento di Bioscienze, Università degli studi di Milano, Milan, Italy, ${ }^{2}$ Istituto di Genetica Molecolare Luigi Luca \\ Cavalli-Sforza, CNR, Pavia, Italy, ${ }^{3}$ IFOM Foundation, Milan, Italy
}

In all the eukaryotic cells, nucleolytic processing (resection) of a double strand DNA break (DSB) is a key step to channel the repair of the lesion toward the homologous recombination, at the expenses of the non-homologous end joining (NHEJ). The coordinated action of several nucleases and helicases generates $3^{\prime}$ single strand (ss) DNA, which is covered by RPA and recombination factors. Molecular details of the process have been first dissected in the model organism Saccharomyces cerevisiae. When DSB ends are occupied by KU, a central component of the NHEJ, the Mre11-Rad50-Xrs2 (MRX) nuclease complex (MRN in human), aided by the associated factors Sae2 (CTIP in human), initiates the resection process, inducing a nick close to the DSB ends. Then, starting from the nick, the nucleases Mre11, Exo1, Dna2, in cooperation with Sgs1 helicase (BLM in human), degrade DNA strand in both the directions, creating the $3^{\prime}$ ssDNA filament. Multiple levels of regulation of the break processing ensure faithful DSB repair, preventing chromosome rearrangements, and genome instability. Here we review the DSB resection process and its regulation in the context of chromatin. Particularly, we focus on proteins that limit DSB resection, acting as physical barriers toward nucleases and helicases. Moreover, we also take into consideration recent evidence regarding functional interplay between DSB repair and RNA molecules nearby the break site.

Keywords: resection barriers, DSB processing, NHEJ, HDR, DNA:RNA hybrid

\section{DSB END PROCESSING}

DSBs are classically defined as broken chromosomes, however uncapped telomere ends and reversed forks are bound and processed by the same factors. In this review we generally focus on broken chromosomes, although proteins, and mechanisms that we mention are active on whole types of DSBs.

In all the eukaryotes, a DSB can be repaired through non-homologous end joining (NHEJ) or homology directed recombination (HDR). Both pathways are organized in distinct steps and sub-pathways, which involve the coordination of several factors and enzymes (Heyer et al., 2010; Symington, 2016). Of note, specific mechanisms are required to process DSB ends containing covalently-bound proteins (such as Topoisomerase), DNA alterations (oxidation, methylation, hairpin formation, and others) and associated RNA molecules (e.g., DNA:RNA hybrids), which interfere with their repair through NHEJ and HDR (Figures 1A-C). Moreover, an irreparable DSB can be eventually processed by telomerase and DNA polymerase alpha-primase ( $\mathrm{Pol} \alpha-$ Prim), together with other factors, leading to de novo telomere addition (Putnam and Kolodner, 2017). Given the heterogeneity and complexity of the mechanisms involved, multiple levels of 
regulation have been identified, determining the repair of a DSB in the different cell cycle phases and chromatin context. Indeed, the uncontrolled DSB processing and repair greatly contribute to chromosome rearrangements (deletions, insertion, translocations), hallmarks of cancer and other pathological conditions associated to genome instability.

The nucleolytic processing (also called resection) of the DSB ends is a critical and finely regulated step to promote HDR over NHEJ. Indeed, the resection process generates an extended $3^{\prime}$-end ssDNA filament, which is then covered by RPA and the recombinase Rad51, depending on the sub-pathway (Symington, 2016).

The DSB resection is carried out by the coordinated actions of several nucleases, among which Mre11, Exo1, and Dna2 are the most involved from yeast to human. According to current models, Dna2 in cooperation with the helicase Sgs1 (BLM in human), and Exo1 process a DSB whose $5^{\prime}$ ends are accessible. Alternatively, a DSB with blocked or chemically modified ends needs the activity of the MRX (MRN in human) complex to initiate the process (Figure 1D). Indeed, in vivo and in vitro data (Neale et al., 2005; Shibata et al., 2014; Reginato et al., 2017; Wang et al., 2017, 2018) have shown that Mre11 is recruited nearby the DSB ends and induces a nick on the $5^{\prime}$-end filament, creating the entry point for both Exo1 and Dna2-Sgs1/BLM (Figure 1D). Then, starting from the nick, MRX/MRN processes the DNA in the $3^{\prime}$-to- $5^{\prime}$ direction till the break site (short-range resection), while Exo1 and Dna2-Sgs1/BLM extensively process the DNA in the $5^{\prime}$-to- $3^{\prime}$ direction (long-range resection) (Figure 1D). Interestingly, recent in vitro data indicate that BLM promotes the EXO1 resection processivity, too (Soniat et al., 2019). This nick-dependent mechanism for resection is activated in $\mathrm{S}$ and G2/M phases through the CDK1-dependent phosphorylation of Sae2 (CTIP in human) (Huertas et al., 2008; Huertas and Jackson, 2009), which associates with the Mre11 complex.

The importance of regulating the DNA ends resection in DSB repair is underlined by the increasing list of factors participating in the reaction in human cells, including the oncosuppressor BRCA1 (Zhao et al., 2019).

Below we review how specific factors and DNA/RNA transactions limit DSB resection, acting as physical barriers toward the nucleases. However, their antagonistic roles in the process appear very dynamic, likely exerting both negative and positive regulations on DSB repair.

\section{NUCLEOSOME-DEPENDENT BARRIER}

There is a general agreement that DNA, wrapped around the histone octamer into the nucleosome, is refractory to be resected due to steric hindrance. Indeed, in yeast the resection of DSBs frequently terminates at nucleosome (Mimitou et al., 2017); moreover, in vitro assays showed that DNA with reconstituted nucleosomes is resected by both Exo1 and Dna2-Sgs1 slower than naked DNA (Adkins et al., 2013). Remarkably, other in vitro results showed that BLM is able to slide nucleosomes, if RPA is added in the assay, promoting DNA resection by EXO1 and DNA2 (Xue et al., 2019). Of importance, the phosphorylation of RPA is critical to limit resection at nucleosomes, interfering with the strand-switching of BLM helicase (Soniat et al., 2019). However, Exo1 can actively resect DNA packed into nucleosomes containing the H2A.Z histone variant, which promotes higher mobility and instability of the octamer (Adkins et al., 2013). As such, the dynamic deposition of H2A.Z, together with other histone modifications, might facilitate the long-range resection by Exo1, with processing rate similar to naked DNA. On the other hand, it has been also shown that H2A.Z and $\mathrm{H} 3.3$ variants facilitate the loading of the NHEJ factors KU and XRCC4 onto DSB, thus limiting resection initiation (Xu et al., 2012; Luijsterburg et al., 2016). Nevertheless, other modifications of the histone core have been recently shown to facilitate the recruitment at DSB of both NHEJ and proresection factors, leading to a more complex scenario. According to several in vivo results, current models support a fundamental role of chromatin remodelers to mobilize and/or dissociate nucleosomes 1-2 kb nearby a DSB, creating the entry-space for repair factors (Shim et al., 2007; Price and D'Andrea, 2013; Clouaire and Legube, 2019; Figure 1D).

\section{KU-DEPENDENT BARRIER}

Soon after a DSB formation, the heterodimer Ku70-80 complex (KU) binds DNA ends in all the cell cycle phases, acting as a platform for the association of several factors involved in NHEJ (Frit et al., 2019). Along with its role in promoting NHEJ, KU plays also fundamental role in limiting chromosome translocations mediated by the annealing of ssDNA repeats in human cells (Weinstock et al., 2006). Indeed, KU-bound DSB ends are resistant to Exo1 and Dna2 processing (Shim et al., 2010; Symington, 2016; Wang et al., 2018), reducing recombination DNA repair by micro-homology mediated end joining (MMEJ, also called alternative end-joining or alt-EJ in higher eukaryotes) and single strand annealing (SSA) mechanisms (Symington, 2016). In yeast, KU-dependent resection barrier is predominant in G1 phase (Clerici et al., 2008), when MRX-Sae2 is not activated by CDK1, or in the absence of functional MRX complex or Sae2 (Mimitou and Symington, 2010). Accordingly, deletion of KU70 partially suppressed the resection defect and sensitivity of sae 2 or mre11 mutants to ionizing radiations (Bonetti et al., 2010; Mimitou and Symington, 2010; Foster et al., 2011).

These and other experimental evidence support the involvement of the Mre11 complex and Sae2/CTIP to overcome the KU barrier, through the nick-dependent resection initiation (Figure 1D). By this model, the short-range resection through the Mre11 complex, together with Sae2/CTIP, is responsible for KU removal from the ends (Chanut et al., 2016; Symington, 2016), leading to a more complex and functional interplay between NHEJ and HDR. This mechanism is also functional at one-ended DSB created at broken DNA replication forks in human cells (Chanut et al., 2016). Moreover, depending upon the organisms, it is known that KU binding to DSB is finely regulated through neddylation (Brown et al., 2015), ubiquitylation (Postow et al., 2008; Feng and Chen, 2012), sumoylation (Hang et al., 2014), acetylation (Kim et al., 2014), and phosphorylation by 


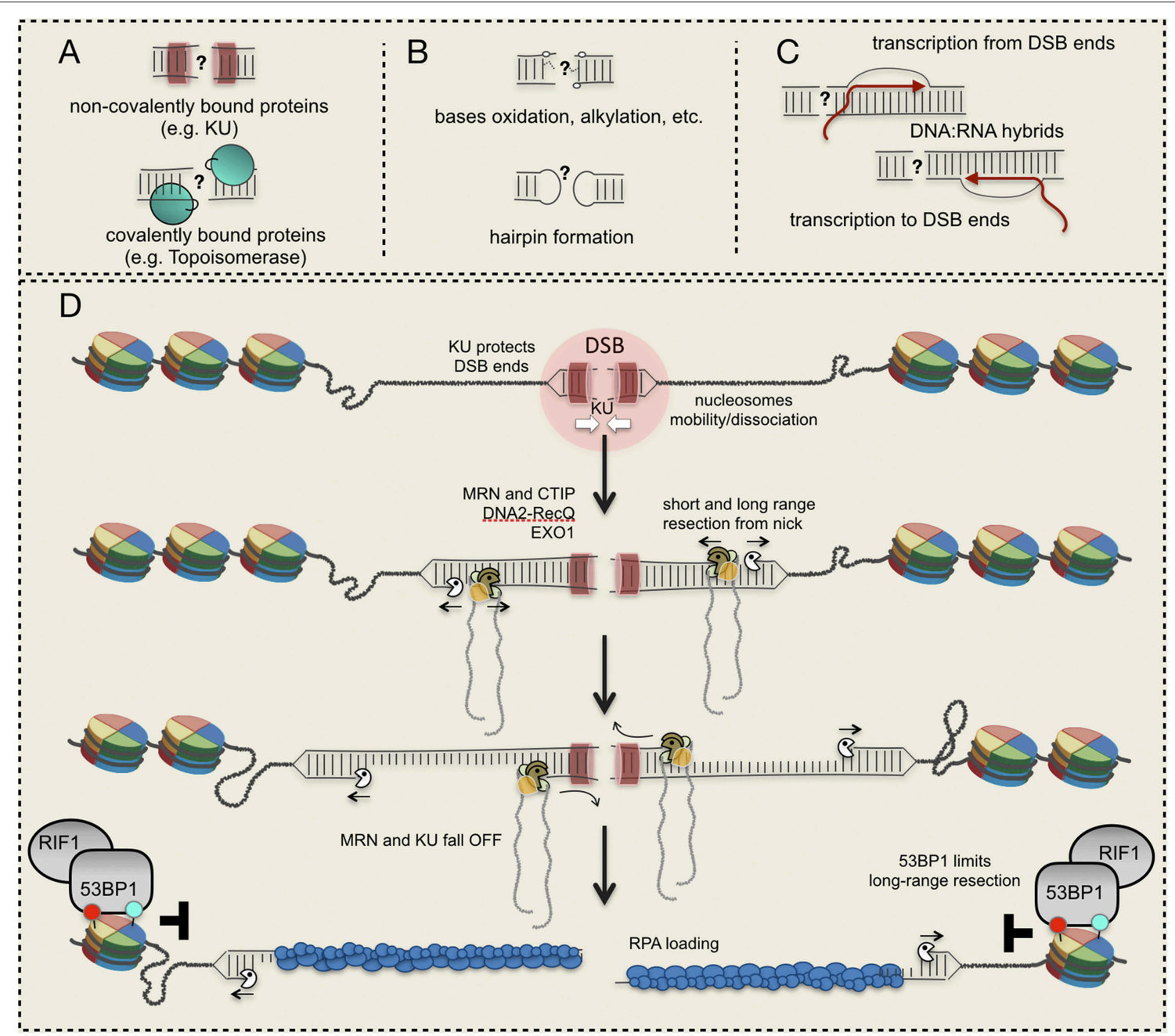

FIGURE 1 | DSB ends and their processing. (A) Proteins bound to DSB ends interfere with resection initiation; (B) structural/chemical modifications of DNA ends require specific processing; (C) DNA:RNA hybrid formation at a DSB; (D) a model to resect a DSB starting from a nick induced by Mre11 nearby the DSB site. Red and light green circles indicate histone modifications. See details in the text.

DNA-PKs (Chan et al., 1999). In particular, neddylation primes ubiquitylation of $\mathrm{KU}$ in human cells, facilitating the release of the complex and associated factors from repaired DNA (Brown et al., 2015). Moreover, it has been shown that the AAA-ATPase p97 also cooperates for the removal of ubiquitinated KU from DSBs, after completion of end joining in human cells (van den Boom et al., 2016). However, it is unknown whether these and/or other post-translational modifications of KU might also control DSB resection initiation through KU stability at the DNA ends.

Further studies will be required to define how these multiple post-translational modifications of KU are conserved throughout evolution, co-exist during the cell cycle, regulate resection, and modulate DSB repair pathways.

\section{BP1-DEPENDENT BARRIER}

The mammalian p53-binding protein 1 (53BP1) and its yeast ortholog Rad9 are important regulators of the DSB repair pathway choice (Panier and Boulton, 2014). Remarkably, 53BP1 and Rad9 act on all types of DSBs, including reversed forks and uncapped telomeres. They are recruited to chromatin through direct recognition of a DSB-specific histone code and their function as an anti-resection factor is conserved throughout evolution. Both 53BP1 and Rad9 act as mediators, linking the upstream kinase ATR/Mec1 to the downstream effector kinases $\mathrm{CHK} 2 / \operatorname{Rad} 53$ and $\mathrm{CHK} 1$. In yeast Rad9 oligomers are recruited to chromatin through three different pathways: (1) the constitutive interaction with the histone $\mathrm{H} 3$ methylated at the K79 residue by Dot1/DOT1L; (2) the binding to the histone H2A phosphorylated at the $\mathrm{S} 129$ residue by Mec1; (3) the interaction with Dpb11/TOPBP1. All of these three pathways cooperate for efficient checkpoint signaling and cell survival after genotoxic treatments throughout the cell cycle.

In higher eukaryotes 53BP1 protects DNA ends from inappropriate $5^{\prime}$ hyper-resection, facilitating NHEJ, and errorfree gene conversion at the expense of mutagenic SSA and alt-EJ 
(Ochs et al., 2016). Of note, extended ssDNA can lead to increased recombination events between repeats that are frequently present in eukaryotic genomes, leading to increased hypermutagenesis at breakpoint junctions (Sinha et al., 2017). Similarly to Rad9, 53BP1 recruitment requires the direct recognition of a DSBspecific histone code: it displays a strong binding affinity for the histone $\mathrm{H} 4$ constitutively mono- or di-methylated at the K20 (Botuyan et al., 2006) and for the histone H2A DSB-induced ubiquitination at K15 (Fradet-Turcotte et al., 2013). Moreover, 53BP1 oligomerization, mediated by DYNLL1, is essential for its recruitment to DSBs (Becker et al., 2018; West et al., 2019). Specifically, 53BP1 barrier is known to antagonize nucleases involved in the long-range resection, although its role to block resection initiation is supported by data in yeast, particularly in mutants affecting short-range resection. Interestingly, it has been shown that Rad9 accumulates at DSB ends in yeast cells lacking SAE2, blocking resection initiation by Dna2-Sgs1 (Bonetti et al., 2015; Ferrari et al., 2015; Yu et al., 2018). Moreover, resection initiation and capture of distant doublestrand ends by CTIP is counteracted by 53BP1 in human cells (Guirouilh-Barbat et al., 2016).

These and other evidence indicate that 53BP1 exerts its action as a resection barrier in an extremely dynamic way, by mutual antagonism with BRCA1 and recruiting several downstream effectors (Panier and Boulton, 2014; Zimmermann and de Lange, 2014). Notably, following DSB-induced phosphorylation by ATM, 53BP1 recruits RIF1, the Shielding complex and the CST/ Pol $\alpha$-Prim complex that fills in the resected DNA end, restoring dsDNA and allowing NHEJ [see a recent review here (Setiaputra and Durocher, 2019)]. It is an open debate whether 53BP1 and its partners exert their function to limit resection directly as a physical barrier to nucleases or indirectly reconstituting processed DNA ends (Setiaputra and Durocher, 2019). Most likely, both hypotheses are true (Figure 2A).

Of note, in the S/G2 phases of the cell cycle BRCA1 promotes phosphatase PP4C-dependent 53BP1 dephosphorylation and RIF1 release (Isono et al., 2017), promoting end resection and directing repair toward HDR. Inactivation not only of 53BP1, but also of its downstream effectors was shown to increase DNA damage tolerance of cancer-prone BRCA $1^{-/-}$cells, most likely potentiating error prone HR pathways and increasing genome instability (Setiaputra and Durocher, 2019).

In addition to BRCA1, other factors and mechanisms modulate the mobility of the 53BP1-dependent barrier. For instance, the $\mathrm{H} 2 \mathrm{~A}$ ubiquitylation by BRCA1-BARD1 recruits the chromatin remodeler SMARCAD1, which then controls 53BP1 repositioning nearby a DSB and promotes long-range resection (Costelloe et al., 2012; Densham et al., 2016). In yeast, the SMARCAD1-ortholog Fun30 also acts on the Rad9barrier, promoting long-range resection (Chen et al., 2012; Eapen et al., 2012; Bantele et al., 2017). Moreover, the Slx4Rtt107 complex counteracts Rad9 binding to Dpb11/TOPBP1 and histones at the break, favoring DSB resection and HDR in yeast (Dibitetto et al., 2016).

It is important to keep in mind that the extensive resection is controlled by other factors and mechanisms than the 53BP1 barrier. For example, in human cells the $5^{\prime}-3^{\prime}$ translocase HELB limits EXO1 and DNA2/BLM nuclease activity (Tkac et al., 2016).

\section{IS THE DNA:RNA HYBRID A BARRIER TO DSB RESECTION?}

It is an open debate how local transcription might interfere with DSB processing and repair. Indeed, DNA transcription might act as a physical barrier to DSB repair, especially during HDR, which requires long-range DSB resection. Accordingly, a reduction of DNA transcription nearby a DSB has been detected in both yeast (Lee et al., 2000; Manfrini et al., 2015) and mammals (Kruhlak et al., 2007; Chou et al., 2010; Shanbhag et al., 2010; Pankotai et al., 2012; Kakarougkas et al., 2014; Ui et al., 2015; Awwad et al., 2017; Iannelli et al., 2017; Vitor et al., 2019). While canonical ongoing transcription is switched off in response to DSB formation, mounting evidence suggests that DSB ends may act as transcriptional promoterlike elements, priming the formation of long non-coding RNA specie. In this context, transcription requires MRNdependent recruitment of RNAPII at DNA lesions (Michelini et al., 2017) or, in the case of DSBs generated at promoterproximal regions, cAbl-dependent tyrosine phosphorylation of RNAPII (Burger et al., 2019). The newly-synthetized noncoding RNAs at DSBs contribute to signal locally DNA damage and facilitate DNA repair (Francia et al., 2012; Wei et al., 2012) and, by changing chromatin structure, also possibly contribute to repress canonical transcription (Burger et al., 2019).

Since RNA synthesis nearby a DSB is both repressed and activated, it is unclear whether the transcription process per se and/or the formation of transcripts might antagonize locally the DSB resection and repair. Indeed, nascent RNA can be utilized as template to repair DSBs in transcribed genes via either error-free cNHEJ in human cells (Chakraborty et al., 2016), or HDR upon its assimilation into broken DNA by Rad52 protein, via an inverse strand exchange mechanism conserved from yeast to human (Keskin et al., 2014; Mazina et al., 2017). There are also evidence that DNA:RNA hybrids, generated at resected or minimally resected DNA ends, regulate the recruitment of RPA, BRCA1, BRCA2, RAD51, and RAD52, promoting HDR (Ohle et al., 2016; Cohen et al., 2018; D’Alessandro et al., 2018; Lu et al., 2018; Burger et al., 2019; Domingo-Prim et al., 2019). Another recent study in human cells showed that DSBs within transcriptionally active genes lead to the formation of R-loops, whose cleavage by the endonuclease XPG promotes an alternative way to initiate DSB resection and HDR (Yasuhara et al., 2018). Of interest, after their recruitment at XPG-processed DSBs, RAD52, and BRCA1 limit the 53BP1-RIF1 barrier. Remarkably, dysfunctions in the XPG-dependent mode to initiate resection lead to elevated NHEJ at transcribed loci and genome instability. Although DNA:RNA hybrids might not antagonize DSB resection initiation, they need to be dismantled by specific helicases or processed by RNases, allowing the HDR repair to proceed (Li et al., 2016; Ohle et al., 2016; Cohen et al., 2018). Interestingly, the RNase EXOSC10, a catalytic subunit of the RNA exosome complex, has been recently 


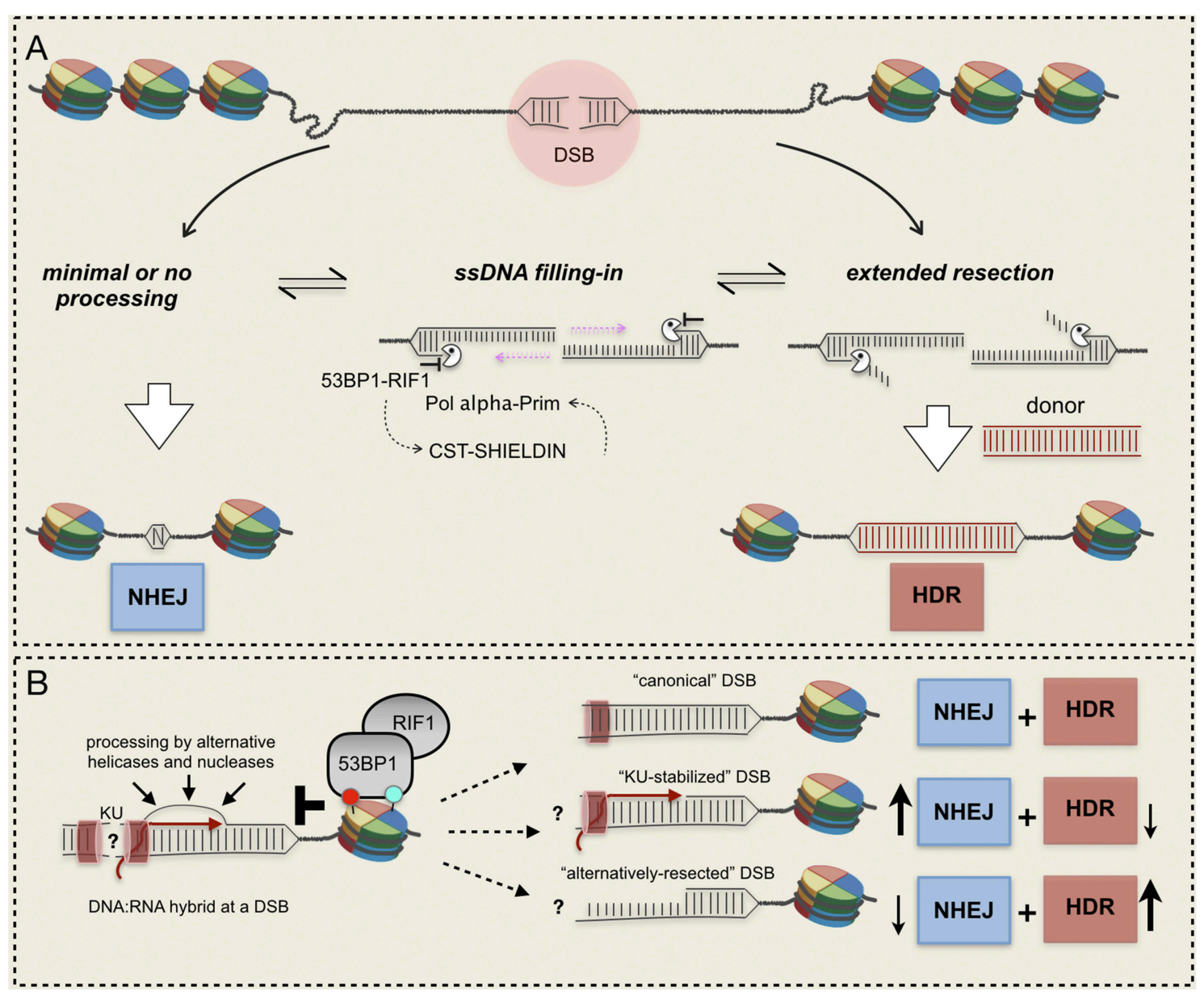

FIGURE 2 | Mechanisms and resection barriers influencing DSB repair pathways choice. (A) 53BP1-dependent axis antagonizes resection and promotes ssDNA re-filling, leading to NHEJ; (B) DNA:RNA hybrids in the context of other barriers can be processed by alternative mechanisms or can persist at the break, unbalancing the DSB repair pathway choice. RNA molecules can be present at the break in active transcribed gene or can be newly-synthetized after a DSB. Red and light green circles indicate histone modifications. See text for details.

involved to clear DNA:RNA hybrids at DSBs, preventing hyperresection and coupling the nucleolytic processing with deposition of RPA and HDR repair in human cells (Domingo-Prim et al., 2019). Similarly, the accumulation of hybrids in cells depleted of Senataxin, a DNA/RNA helicase with R-loop-resolving activity, counteracts the binding of RAD51 and stimulates that of 53BP1 (Cohen et al., 2018), leading to illegitimate repair of broken ends and chromosome translocations (Brustel et al., 2018; Cohen et al., 2018). In this scenario, it is also important to mention that a recent work has reported that high levels of DNA:RNA hybrids at DSBs, due to the inactivation of human RNA binding protein HNRNPD, limit DSB resection, and HDR (Alfano et al., 2019).

Overall, current findings indicate that DNA:RNA hybrids at a DSB both promote and impair resection and HDR (Figure 2B), which might depend on local chromatin context. However, timely formation and dissociation of DNA:RNA hybrids impact on the DSB repair pathway choice and genome stability. Further investigations will be required to understand how the recruitment of the RNAPII complex and RNA synthesis impact locally on DSB resection and repair, favoring NHEJ or HDR.

\section{CONCLUSIVE REMARKS}

Studies from yeast to human have shown that a wide variety of proteins and DNA/RNA transactions modulate resection, altering DSB repair pathway choice. Further investigations will be required to define their functional interplay. Moreover, an open debate regards the DSB resection initiation within active transcribed chromatin. It is unclear how the transcription machinery and the DNA:RNA hybrids influence the DSB repair pathway choice. Do the DNA:RNA hybrids at DSBs interfere with the resection antagonists, rather than with the resection machinery? Do the loading of the resection antagonists (such as $\mathrm{KU}$ and/or 53BP1) at the DSB is influenced by DNA:RNA hybrids?

Other relevant questions regard the role and mechanisms of resection barriers at stall or collapsed replication forks. Indeed, transcription, and the DNA damage response are highly influenced by the chromatin architecture changes occurring during DNA replication. 
Remarkably, factors involved in DSB resection are deregulated in different cancers and genome instability syndromes, being also considered promising therapy targets. Indeed, the importance of all the factors involved in establishing and/or dampening resection barriers clearly emerged by treating tumor cells, which carry mutations in the BRCA1-axis, with the PARP1 inhibitor Olaparib. Notably, inactivation of the 53BP1-dependent resection barrier dramatically reduces the effectiveness of the treatment on BRCA1 defective cells, possibly leading to genome instability, poor prognosis, and cancer relapse (Lord and Ashworth, 2017; Setiaputra and Durocher, 2019).

\section{REFERENCES}

Adkins, N. L., Niu, H., Sung, P., and Peterson, C. L. (2013). Nucleosome dynamics regulates DNA processing. Nat. Struct. Molecul. Biol. 20, 836-842. doi: $10.1038 / \mathrm{nsmb} .2585$

Alfano, L., Caporaso, A., Altieri, A., Dell'Aquila, M., Landi, C., Bini, L., et al. (2019). Depletion of the RNA binding protein HNRNPD impairs homologous recombination by inhibiting DNA-end resection and inducing Rloop accumulation. Nucleic Acids Res. 47, 4068-4085. doi: 10.1093/nar/gkz076

Awwad, S. W., Abu-Zhayia, E. R., Guttmann-Raviv, N., and Ayoub, N. (2017). NELF-E is recruited to DNA double-strand break sites to promote transcriptional repression and repair. EMBO Rep. 18, 745-764. doi: 10.15252/embr.201643191

Bantele, S. C., Ferreira, P., Gritenaite, D., Boos, D., and Pfander, B. (2017). Targeting of the Fun30 nucleosome remodeller by the Dpb11 scaffold facilitates cell cycle-regulated DNA end resection. eLife 6:e21687. doi: 10.7554/eLife.21687

Becker, J. R., Cuella-Martin, R., Barazas, M., Liu, R., Oliveira, C., Oliver, A. W., et al. (2018). The ASCIZ-DYNLL1 axis promotes 53BP1-dependent nonhomologous end joining and PARP inhibitor sensitivity. Nat. Commun. 9:5406. doi: 10.1038/s41467-018-07855-x

Bonetti, D., Clerici, M., Manfrini, N., Lucchini, G., and Longhese, M. P. (2010). The MRX complex plays multiple functions in resection of Yku- and Rif2-protected DNA ends. PLoS ONE 5:e14142. doi: 10.1371/journal.pone.0014142

Bonetti, D., Villa, M., Gobbini, E., Cassani, C., Tedeschi, G., and Longhese, M. P. (2015). Escape of Sgs1 from Rad9 inhibition reduces the requirement for Sae2 and functional MRX in DNA end resection. EMBO Rep. 16, 351-361. doi: 10.15252/embr.201439764

Botuyan, M. V., Lee, J., Ward, I. M., Kim, J. E., Thompson, J. R., Chen, J., et al. (2006). Structural basis for the methylation state-specific recognition of histone H4-K20 by 53BP1 and Crb2 in DNA repair. Cell 127, 1361-1373. doi: 10.1016/j.cell.2006.10.043

Brown, J. S., Lukashchuk, N., Sczaniecka-Clift, M., Britton, S., le Sage, C., Calsou, P., et al. (2015). Neddylation promotes ubiquitylation and release of Ku from DNA-damage sites. Cell Rep. 11, 704-714. doi: 10.1016/j.celrep.2015.03.058

Brustel, J., Kozik, Z., Gromak, N., Savic, V., and Sweet, S. M. M. (2018). Large XPF-dependent deletions following misrepair of a DNA double strand break are prevented by the RNA:DNA helicase Senataxin. Sci. Rep. 8:3850. doi: $10.1038 /$ s41598-018-21806-y

Burger, K., Schlackow, M., and Gullerova, M. (2019). Tyrosine kinase c-Abl couples RNA polymerase II transcription to DNA double-strand breaks. Nucleic Acids Res. 47, 3467-3484. doi: 10.1093/nar/gkz024

Chakraborty, A., Tapryal, N., Venkova, T., Horikoshi, N., Pandita, R. K., Sarker, A. H., et al. (2016). Classical non-homologous end-joining pathway utilizes nascent RNA for error-free double-strand break repair of transcribed genes. Nat. Commun. 7:13049. doi: 10.1038/ncomms13049

Chan, D. W., Ye, R., Veillette, C. J., and Lees-Miller, S. P. (1999). DNA-dependent protein kinase phosphorylation sites in Ku 70/80 heterodimer. Biochemistry 38, 1819-1828. doi: 10.1021/bi982584b

Chanut, P., Britton, S., Coates, J., Jackson, S. P., and Calsou, P. (2016). Coordinated nuclease activities counteract $\mathrm{Ku}$ at single-ended DNA double-strand breaks. Nat. Commun. 7:12889. doi: 10.1038/ncomms12889

\section{AUTHOR CONTRIBUTIONS}

AP conceived the idea. All authors wrote the manuscript.

\section{FUNDING}

This work was supported by grants to AP from Associazione Italiana Ricerca sul Cancro [AIRC-IG-15488] and [AIRC-IG19917], and from Ministero Istruzione Università e Ricerca [PRIN-2015LZE994]; GL was supported by a grant from Associazione Italiana Ricerca sul Cancro [AIRC-IG-17714].

Chen, X., Cui, D., Papusha, A., Zhang, X., Chu, C. D., Tang, J., et al. (2012). The Fun30 nucleosome remodeller promotes resection of DNA double-strand break ends. Nature 489, 576-580. doi: 10.1038/nature11355

Chou, D. M., Adamson, B., Dephoure, N. E., Tan, X., Nottke, A. C., Hurov, K. E., et al. (2010). A chromatin localization screen reveals poly (ADP ribose)regulated recruitment of the repressive polycomb and NuRD complexes to sites of DNA damage. Proc. Natl. Acad. Sci. U.S.A. 107, 18475-18480. doi: $10.1073 /$ pnas.1012946107

Clerici, M., Mantiero, D., Guerini, I., Lucchini, G., and Longhese, M. P. (2008). The Yku70-Yku80 complex contributes to regulate double-strand break processing and checkpoint activation during the cell cycle. EMBO Rep. 9:810-818. doi: 10.1038/embor.2008.121

Clouaire, T., and Legube, G. (2019). A snapshot on the cis chromatin response to DNA double-strand breaks. Trends Genet. 35, 330-345. doi: 10.1016/j.tig.2019.02.003

Cohen, S., Puget, N., Lin, Y. L., Clouaire, T., Aguirrebengoa, M., Rocher, V., et al. (2018). Senataxin resolves RNA:DNA hybrids forming at DNA double-strand breaks to prevent translocations. Nat. Commun. 9:533. doi: 10.1038/s41467-018-02894-w

Costelloe, T., Louge, R., Tomimatsu, N., Mukherjee, B., Martini, E., Khadaroo, B., et al. (2012). The yeast Fun 30 and human SMARCAD1 chromatin remodellers promote DNA end resection. Nature 489, 581-584. doi: 10.1038/nature11353

D'Alessandro, G., Whelan, D. R., Howard, S. M., Vitelli, V., Renaudin, X., Adamowicz, M., et al. (2018). BRCA2 controls DNA:RNA hybrid level at DSBs by mediating RNase H2 recruitment. Nat. Commun. 9:5376. doi: 10.1038/s41467-018-07799-2

Densham, R. M., Garvin, A. J., Stone, H. R., Strachan, J., Baldock, R. A., DazaMartin, M., et al. (2016). Human BRCA1-BARD1 ubiquitin ligase activity counteracts chromatin barriers to DNA resection. Nat. Struct. Mol. Biol. 23, 647-655. doi: 10.1038/nsmb.3236

Dibitetto, D., Ferrari, M., Rawal, C. C., Balint, A., Kim, T., Zhang, Z., et al. (2016). Slx 4 and Rtt107 control checkpoint signalling and DNA resection at double-strand breaks. Nucleic Acids Res. 44, 669-682. doi: 10.1093/nar/gkv1080

Domingo-Prim, J., Endara-Coll, M., Bonath, F., Jimeno, S., Prados-Carvajal, R., Friedlander, M. R., et al. (2019). EXOSC10 is required for RPA assembly and controlled DNA end resection at DNA double-strand breaks. Nat. Commun. 10:2135. doi: 10.1038/s41467-019-10153-9

Eapen, V. V., Sugawara, N., Tsabar, M., Wu, W. H., and Haber, J. E. (2012). The Saccharomyces cerevisiae chromatin remodeler Fun30 regulates DNA end resection and checkpoint deactivation. Mol. Cell. Biol. 32, 4727-4740. doi: 10.1128/MCB.00566-12

Feng, L., and Chen, J. (2012). The E3 ligase RNF8 regulates KU80 removal and NHEJ repair. Nat. Struct. Mol. Biol. 19, 201-206. doi: 10.1038/nsmb.2211

Ferrari, M., Dibitetto, D., De Gregorio, G., Eapen, V. V., Rawal, C. C., Lazzaro, F., et al. (2015). Functional interplay between the 53BP1-ortholog Rad9 and the Mre11 complex regulates resection, end-tethering and repair of a double-strand break. PLoS Genet. 11:e1004928. doi: 10.1371/journal.pgen.10 04928

Foster, S. S., Balestrini, A., and Petrini, J. H. (2011). Functional interplay of the Mre11 nuclease and $\mathrm{Ku}$ in the response to replication-associated DNA damage. Mol. Cell. Biol. 31, 4379-4389. doi: 10.1128/MCB.05854-11 
Fradet-Turcotte, A., Canny, M. D., Escribano-Diaz, C., Orthwein, A., Leung, C. C., Huang, H.,et al. (2013). 53BP1 is a reader of the DNA-damage-induced H2A Lys 15 ubiquitin mark. Nature 499, 50-54. doi: 10.1038/nature12318

Francia, S., Michelini, F., Saxena, A., Tang, D., de Hoon, M., Anelli, V., et al. (2012). Site-specific DICER and DROSHA RNA products control the DNA-damage response. Nature 488, 231-235. doi: 10.1038/nature11179

Frit, P., Ropars, V., Modesti, M., Charbonnier, J. B., and Calsou, P. (2019). Plugged into the Ku-DNA hub: The NHEJ network. Prog. Biophys. Mol. Biol. 6:S0079-6107(18)30251-7. doi: 10.1016/j.pbiomolbio.2019.03.001

Guirouilh-Barbat, J., Gelot, C., Xie, A., Dardillac, E., Scully, R., and Lopez, B. S. (2016). 53BP1 protects against CtIP-dependent capture of ectopic chromosomal sequences at the junction of distant double-strand breaks. PLoS Genet. 12:e1006230. doi: 10.1371/journal.pgen.1006230

Hang, L. E., Lopez, C. R., Liu, X., Williams, J. M., Chung, I., Wei, L., et al. (2014). Regulation of Ku-DNA association by Yku70 C-terminal tail and SUMO modification. J. Biol. Chem. 289, 10308-10317. doi: 10.1074/jbc.M113.526178

Heyer, W. D., Ehmsen, K. T., and Liu, J. (2010). Regulation of homologous recombination in eukaryotes. Annu. Rev. Genet. 44, 113-139. doi: 10.1146/annurev-genet-051710-150955

Huertas, P., Cortes-Ledesma, F., Sartori, A. A., Aguilera, A., and Jackson, S. P. (2008). CDK targets Sae2 to control DNA-end resection and homologous recombination. Nature 455, 689-692. doi: 10.1038/nature07215

Huertas, P., and Jackson, S. P. (2009). Human CtIP mediates cell cycle control of DNA end resection and double strand break repair. J. Biol. Chem. 284, 9558-9565. doi: 10.1074/jbc.M808906200

Iannelli, F., Galbiati, A., Capozzo, I., Nguyen, Q., Magnuson, B., Michelini, F., et al. (2017). A damaged genome's transcriptional landscape through multilayered expression profiling around in situ-mapped DNA double-strand breaks. Nat. Commun. 8:15656. doi: 10.1038/ncomms15656

Isono, M., Niimi, A., Oike, T., Hagiwara, Y., Sato, H., Sekine, R., et al. (2017). BRCA1 directs the repair pathway to homologous recombination by promoting 53BP1 dephosphorylation. Cell Rep. 18, 520-532. doi: 10.1016/j.celrep.2016.12.042

Kakarougkas, A., Ismail, A., Chambers, A. L., Riballo, E., Herbert, A. D., Kunzel, J., et al. (2014). Requirement for PBAF in transcriptional repression and repair at DNA breaks in actively transcribed regions of chromatin. Mol. Cell 55, 723-732. doi: 10.1016/j.molcel.2014.06.028

Keskin, H., Shen, Y., Huang, F., Patel, M., Yang, T., Ashley, K., et al. (2014). Transcript-RNA-templated DNA recombination and repair. Nature 515, 436-439. doi: 10.1038/nature13682

Kim, K. B., Kim, D. W., Park, J. W., Jeon, Y. J., Kim, D., Rhee, S., et al. (2014). Inhibition of Ku70 acetylation by INHAT subunit SET/TAF-I $\beta$ regulates Ku70-mediated DNA damage response. Cell. Molecul. Life Sci. 71, 2731-2745. doi: 10.1007/s00018-013-1525-8

Kruhlak, M., Crouch, E. E., Orlov, M., Montano, C., Gorski, S. A., Nussenzweig, A., et al. (2007). The ATM repair pathway inhibits RNA polymerase I transcription in response to chromosome breaks. Nature 447, 730-734. doi: $10.1038 /$ nature 05842

Lee, S. E., Pellicioli, A., Demeter, J., Vaze, M. P., Gasch, A. P., Malkova, A., et al. (2000). Arrest, adaptation, and recovery following a chromosome doublestrand break in Saccharomyces cerevisiae. Cold Spring Harb. Symp. Quant. Biol. 65, 303-314. doi: 10.1101/sqb.2000.65.303

Li, L., Germain, D. R., Poon, H. Y., Hildebrandt, M. R., Monckton, E. A., McDonald, D., et al. (2016). DEAD Box 1 facilitates removal of RNA and homologous recombination at DNA double-strand breaks. Mol. Cell. Biol. 36, 2794-2810. doi: 10.1128/MCB.00415-16

Lord, C. J., and Ashworth, A. (2017). PARP inhibitors: synthetic lethality in the clinic. Science 355, 1152-1158. doi: 10.1126/science.aam7344

Lu, W. T., Hawley, B. R., Skalka, G. L., Baldock, R. A., Smith, E. M., Bader, A. S., et al. (2018). Drosha drives the formation of DNA:RNA hybrids around DNA break sites to facilitate DNA repair. Nat. Commun. 9:532. doi: 10.1038/s41467-018-02893-x

Luijsterburg, M. S., de Krijger, I., Wiegant, W. W., Shah, R. G., Smeenk, G., de Groot, A. J. L., et al. (2016). PARP1 links CHD2-mediated chromatin expansion and H3.3 deposition to DNA repair by non-homologous end-joining. Mol. Cell 61, 547-562. doi: 10.1016/j.molcel.2016.01.019

Manfrini, N., Clerici, M., Wery, M., Colombo, C. V., Descrimes, M., Morillon, A., et al. (2015). Resection is responsible for loss of transcription around a double-strand break in Saccharomyces cerevisiae. eLife 4:e08942. doi: 10.7554/eLife.08942

Mazina, O. M., Keskin, H., Hanamshet, K., Storici, F., and Mazin, A. V. (2017) Rad52 inverse strand exchange drives RNA-templated DNA double-strand break repair. Molecul. Cell 67, 19-29.e13. doi: 10.1016/j.molcel.2017.05.019

Michelini, F., Pitchiaya, S., Vitelli, V., Sharma, S., Gioia, U., Pessina, F., et al. (2017). Damage-induced lncRNAs control the DNA damage response through interaction with DDRNAs at individual double-strand breaks. Nat. Cell Biol. 19, 1400-1411. doi: 10.1038/ncb3643

Mimitou, E. P., and Symington, L. S. (2010). Ku prevents Exol and Sgs1-dependent resection of DNA ends in the absence of a functional MRX complex or Sae2. EMBO J. 29, 3358-3369. doi: 10.1038/emboj.2010.193

Mimitou, E. P., Yamada, S., and Keeney, S. (2017). A global view of meiotic doublestrand break end resection. Science 355, 40-45. doi: 10.1126/science.aak9704

Neale, M. J., Pan, J., and Keeney, S. (2005). Endonucleolytic processing of covalent protein-linked DNA double-strand breaks. Nature 436, 1053-1057. doi: $10.1038 /$ nature 03872

Ochs, F., Somyajit, K., Altmeyer, M., Rask, M. B., Lukas, J., and Lukas, C. (2016). 53BP1 fosters fidelity of homology-directed DNA repair. Nat. Struct. Mol. Biol. 23, 714-721. doi: 10.1038/nsmb.3251

Ohle, C., Tesorero, R., Schermann, G., Dobrev, N., Sinning, I., and Fischer, T. (2016). Transient RNA-DNA hybrids are required for efficient double-strand break repair. Cell 167, 1001-1013.e1007. doi: 10.1016/j.cell.2016.10.001

Panier, S., and Boulton, S. J. (2014). Double-strand break repair: 53BP1 comes into focus. Nat. Rev. Molecul. Cell Biol. 15, 7-18. doi: 10.1038/nrm3719

Pankotai, T., Bonhomme, C., Chen, D., and Soutoglou, E. (2012). DNAPKcsdependent arrest of RNA polymerase II transcription in the presence of DNA breaks. Nat. Struct. Mol. Biol. 19, 276-282. doi: 10.1038/nsmb.2224

Postow, L., Ghenoiu, C., Woo, E. M., Krutchinsky, A. N., Chait, B. T., and Funabiki, H. (2008). Ku80 removal from DNA through double strand breakinduced ubiquitylation. J. Cell Biol. 182, 467-479. doi: 10.1083/jcb.2008 02146

Price, B. D., and D'Andrea, A. D. (2013). Chromatin remodeling at DNA doublestrand breaks. Cell 152, 1344-1354. doi: 10.1016/j.cell.2013.02.011

Putnam, C. D., and Kolodner, R. D. (2017). Pathways and mechanisms that prevent genome instability in Saccharomyces cerevisiae. Genetics 206, 1187-1225. doi: 10.1534/genetics.112.145805

Reginato, G., Cannavo, E., and Cejka, P. (2017). Physiological protein blocks direct the Mre11-Rad50-Xrs2 and Sae2 nuclease complex to initiate DNA end resection. Genes Dev. 31, 2325-2330. doi: 10.1101/gad.308254.117

Setiaputra, D., and Durocher, D. (2019). Shieldin - the protector of DNA ends. EMBO Rep. 20:e47560. doi: 10.15252/embr.201847560

Shanbhag, N. M., Rafalska-Metcalf, I. U., Balane-Bolivar, C., Janicki, S. M., and Greenberg, R. A. (2010). ATM-dependent chromatin changes silence transcription in cis to DNA double-strand breaks. Cell 141, 970-981. doi: 10.1016/j.cell.2010.04.038

Shibata, A., Moiani, D., Arvai, A. S., Perry, J., Harding, S. M., Genois, M. M., et al. (2014). DNA double-strand break repair pathway choice is directed by distinct MRE11 nuclease activities. Mol. Cell 53, 7-18. doi: 10.1016/j.molcel.2013. 11.003

Shim, E. Y., Chung, W. H., Nicolette, M. L., Zhang, Y., Davis, M., Zhu, Z., et al. (2010). Saccharomyces cerevisiae Mre11/Rad50/Xrs2 and Ku proteins regulate association of Exo1 and Dna2 with DNA breaks. EMBO J. 29, 3370-3380. doi: 10.1038/emboj.2010.219

Shim, E. Y., Hong, S. J., Oum, J. H., Yanez, Y., Zhang, Y., and Lee, S. E. (2007). RSC mobilizes nucleosomes to improve accessibility of repair machinery to the damaged chromatin. Mol. Cell. Biol. 27, 1602-1613. doi: 10.1128/MCB.01956-06

Sinha, S., Li, F., Villarreal, D., Shim, J. H., Yoon, S., Myung, K., et al. (2017). Microhomology-mediated end joining induces hypermutagenesis at breakpoint junctions. PLoS Genet. 13:e1006714. doi: 10.1371/journal.pgen.1006714

Soniat, M. M., Myler, L. R., Kuo, H. C., Paull, T. T., and Finkelstein, I. J. (2019). RPA phosphorylation inhibits DNA resection. Mol. Cell. doi: 10.1016/j.molcel.2019.05.005. [Epub ahead of print].

Symington, L. S. (2016). Mechanism and regulation of DNA end resection in eukaryotes. Crit. Rev. Biochem. Mol. Biol. 51, 195-212. doi: 10.3109/10409238.2016.1172552 
Tkac, J., Xu, G., Adhikary, H., Young, J. T. F., Gallo, D., Escribano-Diaz, C., et al. (2016). HELB is a feedback inhibitor of DNA end resection. Mol. Cell 61, 405-418. doi: 10.1016/j.molcel.2015.12.013

Ui, A., Nagaura, Y., and Yasui, A. (2015). Transcriptional elongation factor ENL phosphorylated by ATM recruits polycomb and switches off transcription for DSB repair. Mol. Cell 58, 468-482. doi: 10.1016/j.molcel.2015.03.023

van den Boom, J., Wolf, M., Weimann, L., Schulze, N., Li, F., Kaschani, F., et al. (2016). VCP/p97 extracts sterically trapped Ku70/80 rings from DNA in double-strand break repair. Mol. Cell 64, 189-198. doi: 10.1016/j.molcel.2016.08.037

Vitor, A. C., Sridhara, S. C., Sabino, J. C., Afonso, A. I., Grosso, A. R., Martin, R. M., et al. (2019). Single-molecule imaging of transcription at damaged chromatin. Sci. Adv. 5:eaau1249. doi: 10.1126/sciadv.aau1249

Wang, W., Daley, J. M., Kwon, Y., Krasner, D. S., and Sung, P. (2017). Plasticity of the Mre11-Rad50-Xrs2-Sae2 nuclease ensemble in the processing of DNAbound obstacles. Genes Dev. 31, 2331-2336. doi: 10.1101/gad.307900.117

Wang, W., Daley, J. M., Kwon, Y., Xue, X., Krasner, D. S., Miller, A. S., et al. (2018). A DNA nick at Ku-blocked double-strand break ends serves as an entry site for exonuclease 1 (Exo1) or Sgs1-Dna2 in long-range DNA end resection. J. Biol. Chem. 293, 17061-17069. doi: 10.1074/jbc.RA118.004769

Wei, W., Ba, Z., Gao, M., Wu, Y., Ma, Y., Amiard, S., et al. (2012). A role for small RNAs in DNA double-strand break repair. Cell 149, 101-112. doi: 10.1016/j.cell.2012.03.002

Weinstock, D. M., Elliott, B., and Jasin, M. (2006). A model of oncogenic rearrangements: differences between chromosomal translocation mechanisms and simple double-strand break repair. Blood 107, 777-780. doi: 10.1182/blood-2005-06-2437

West, K. L., Kelliher, J. L., Xu, Z., An, L., Reed, M. R., Eoff, R. L., et al. (2019). LC8/DYNLL1 is a 53BP1 effector and regulates checkpoint activation. Nucleic Acids Res. 47, 6236-6249. doi: 10.1093/nar/gkz263

$\mathrm{Xu}$, Y., Ayrapetov, M. K., Xu, C., Gursoy-Yuzugullu, O., Hu, Y., and Price, B. D. (2012). Histone H2A.Z controls a critical chromatin remodeling step required for DNA double-strand break repair. Mol. Cell 48, 723-733. doi: 10.1016/j.molcel.2012.09.026
Xue, C., Wang, W., Crickard, J. B., Moevus, C. J., Kwon, Y., Sung, P., et al. (2019). Regulatory control of Sgs1 and Dna2 during eukaryotic DNA end resection. Proc. Natl. Acad. Sci. U.S.A. 116, 6091-6100. doi: 10.1073/pnas.18192 76116

Yasuhara, T., Kato, R., Hagiwara, Y., Shiotani, B., Yamauchi, M., Nakada, S., et al. (2018). Human Rad52 promotes XPG-mediated R-loop processing to initiate transcription-associated homologous recombination repair. Cell 175, 558-570.e511. doi: 10.1016/j.cell.2018. 08.056

Yu, T. Y., Kimble, M. T., and Symington, L. S. (2018). Sae2 antagonizes Rad9 accumulation at DNA double-strand breaks to attenuate checkpoint signaling and facilitate end resection. Proc. Natl. Acad. Sci. U.S.A. 115, E11961-E11969. doi: 10.1073/pnas.18165 39115

Zhao, W., Wiese, C., Kwon, Y., Hromas, R., and Sung, P. (2019). The BRCA tumor suppressor network in chromosome damage repair by homologous recombination. Annu. Rev. Biochem. 88:221-245. doi: 10.1146/annurev-biochem-013118-1 11058

Zimmermann, M., and de Lange, T. (2014). 53BP1: pro choice in DNA repair. Trends Cell Biol. 24, 108-117. doi: 10.1016/j.tcb.2013. 09.003

Conflict of Interest Statement: The authors declare that the research was conducted in the absence of any commercial or financial relationships that could be construed as a potential conflict of interest.

Copyright $\odot 2019$ Marini, Rawal, Liberi and Pellicioli. This is an open-access article distributed under the terms of the Creative Commons Attribution License (CC BY).

The use, distribution or reproduction in other forums is permitted, provided the original author(s) and the copyright owner(s) are credited and that the original publication in this journal is cited, in accordance with accepted academic practice. No use, distribution or reproduction is permitted which does not comply with these terms. 